\title{
The work of the Somali Counselling Project in the UK
}

\author{
Omar E. Dihour, Project Leader, The Somali Counselling Project, 28 Commercial \\ Street, Toynbee Hall, London E1 6LR (Correspondence); and ANTHONY J. PELOSI, \\ Research Fellow in Clinical Epidemiology, General Practice Research Unit, Institute \\ of Psychiatry, Denmark Hill, London SE5 8AF
}

The Somali Counselling Project was established in London's East End in December 1986 with the support of a grant from the City Parochial Foundation. It offers social support and psychosocial counselling to Somalis and other culturally related peoples from the Horn of Africa who are living in the United Kingdom. Its aims are: to advise on social, administrative and financial problems; to help clients make effective use of mainstream health services; to prevent and treat emotional disorder; and to provide administrative and emotional assistance to those with uncertain immigration status.

\section{Background}

The Somalis in Britain form two distinct groups. Seafarers have been emigrating to this country from the former British Somaliland Protectorate since the early 20 th century. These ageing ex-sailors now live in ports such as the East End of London, Liverpool, and Cardiff. Some moved to work in factories in the Midlands and there are communities in Sheffield and Middlesborough. Many are single or separated from their families and they often live in seamen's hostels. Poor English and a poor level of formal education have been barriers to employment. The second group consists mainly of political refugees who have been coming to Britain since 1980 . Many are exgovernment officials and their families. Over $50 \%$ are women and children and in many cases the male adults of the families have been unable to leave Somalia.

The Somalis are one of the most disadvantaged ethnic minorities in Britain. They are smaller in number than some other groups and their problems have therefore tended to be neglected. There are approximately 13,000 Somalis and an uncertain number of culturally related peoples in the United Kingdom; the largest community is in London with 7,000 people, of whom 5,000 live in the Tower Hamlets area.

\section{The work of the Somali Counselling Project}

There are two members of staff: Dr Omar Dihoud, a Somali psychiatrist, and Ms Amina Hussein, a
British-born woman of Somalian background, who is the part-time secretary. In addition, eight volunteer workers are able to devote varying amounts of time to counselling and supporting clients.

Between mid-1987 and the end of 1988 an average of two new clients per day with a wide range of social, personal and health difficulties were seen. Most live in London but assistance is also given to people in other parts of the United Kingdom and occasionally to east Africans living in other European countries.

\section{Liaison with social services}

The Project works with social services departments, providing translation services and advice on child care, psychiatric and health issues. Because of language barriers some Somalis are not fully aware of social benefits provision and the Project frequently advises on statutory support with help in the completion of claims.

\section{Housing}

The Somali Counselling Project (SCP) is often asked to intervene with the housing authorities. This may involve examination of clients' housing rights and contact with housing departments to explain the difficulties. Contacts are made with lawyers and with local social services where appropriate. Homelessness is a frequent reason for seeking help and recent changes in Social Security regulations have worsened this problem. Homelessness may arise in those who have gone to towns in the North of England but then feel isolated and return to London. We have a network of contacts with hostels (including Church and refugee hostels) and with rental agencies in several parts of London.

\section{Marital and family problems}

Reasons for marital breakdown include financial difficulties (often with poor management of money), isolation of the wives, and difficulties in acculturation. Women appear to bear the brunt of subsequent difficulties; even though in Islamic law men have the first claim to child custody, Somali women in Britain usually take the children. 


\section{Education}

The Project advises on higher educational opportunities for young and older refugees. English lessons are arranged for new arrivals and some families are helped with, for example, school application forms and school reports.

\section{Mental and physical health}

There seems to be a high rate of physical and mental illness in the Somali community. There are many reasons for this, such as the stresses of migration, social isolation, economic deprivation and the problems of acculturation (Berry, 1988). Inadequate housing and a high rate of unemployment affect both physical and mental health. In certain areas, Somalis have to deal with the stresses due to racial intolerance, the psychological sequelae of which have been described in other ethnic groups (see, for example, Fernando, 1984; Littlewood \& Lipsedge, 1988); however, many Somalis do not accept that they could be discriminated against on the grounds of race and we have gained the impression that this can make it more difficult to deal effectively with this problem. Also, cultural differences and language barriers often present effective use of the available health services (see case reports below).

In addition, many new arrivals are subject to the unique stresses encountered by political refugees. This has been studied in clinical settings in several different groups of resettled refugees (see Miserez, 1988). Some clients have suffered imprisonment and torture (Amnesty International, 1984). Political upheavals have often led to family separations and for many there is ongoing uncertainty about the fate of relatives remaining in Africa. The current fighting in Northern Somalia has been a further source of distress and many clients have suffered recent bereavements. Prolonged problems with immigration status can arise and, in some cases, there is an extreme fear of being returned to the country of origin.

Communication difficulties leading to inadequate use of mainstream health services are a particular problem in mental illness and emotional disorders. One of Dr Dihoud's main activities has been to provide a consultation service for general practitioners, hospitals, social workers and prison doctors. This involves advice on the manifestations of certain mental illnesses and translation assistance. Attendance at psychiatric clinics and day centres is encouraged in those with more serious disorder. We are also involved in shared community care of psychiatrically ill clients.

Discussion of emotional difficulties in the clients' own language has been valuable and this is sometimes undertaken by volunteer workers under supervision. Anxiety management techniques are often suggested. Brief family counselling has been effective for some problems. At times, clients' health has been improved simply by encouragement of compliance with medication prescribed by hospitals or family doctors. Often, attention to social and immigration problems has led to improvement in mental state.

When there are complex psychiatric problems and doubts about diagnosis and the presence of physical illness, full clinical assessment at short notice is available at a clinic for refugees we run at the Maudsley Hospital.

\section{Examples of problems in clients with severe difficulties}

To illustrate some of the problems encountered we have summarised the cases of 30 refugee clients who presented between January 1987 and March 1988. These are representative only of those with severe social, emotional and/or health difficulties.

This selected group consists of 15 females and 15 males. Almost all have been in Britain for two to three years. The average age is in the mid-twenties. Marital problems were common in the females: five women were divorced and one was separated; there was one widow. One of the men was separated from his wife. Only one client was in full-time employment outside the home and there was one full-time student. Problems can be briefly classified as follows: 24 out of 30 had one or more social problems which included housing, educational and immigration difficulties; ten had physical illness; 24 had serious emotional disturbance.

Of those with serious emotional disturbance, nine had symptoms and signs of psychosis. The other 15 mainly showed symptoms of depression and anxiety. Agoraphobic symptoms were seen in four of the women. Substance abuse, of alcohol and/or khat (a stimulant drug frequently used in the Horn of Africa, [Kirkorian, 1984]), was considered the main source of psychological disturbance in two men. All 24 of these selected clients had psychiatric symptoms of clinical severity and in most cases these could be attributed to, or were exacerbated by, past upheavals and ongoing social problems.

\section{Case examples}

Only a superficial impression of the problems brought to the Project can be conveyed using group data as above. Brief case descriptions are therefore given below. In some, the interaction of social, physical and psychological problems is apparent.

Case 1. The Kensington and Chelsea Social Services Department referred a Somali woman who had moved from Tower Hamlets and was now living in a bed and breakfast hotel. She had four children between the ages of 6 
months and 11 years. She was the wife of a seafarer and had lived in UK for 18 months. She had left her husband because of violence at home. The children did not speak English and one showed severe behavioural disturbances. The mother also spoke no English and did not know her address or her children's school. We liaised with the Social Services in assessing the problems which included nonaccidental injury of the children. A lawyer was found and the family was placed again in their own flat; the husband had to leave. Problems with neighbours remain and the SCP provides ongoing emotional support.

Case 2. A 40 year-old woman, in the UK for nine years with her seafarer husband, sought help for feelings of depression which she attributed to housing and family problems. There is a family history of atopy and two children have asthma and eczema. The client was very worried that the children's health was being affected by dampness and cockroaches in the home. She was depressed but, in addition, was found to be profoundly hypothyroid. Her GP was aware of the hypothyroidism but the client did not comply with thyroxine replacement therapy. With the help of a Somalian neighbour, Dr Dihoud has successfully encouraged her to take thyroxine regularly, with improvement in the depression. Housing problems remain despite the efforts of the Project and the GP.

Case 3. A 25 year-old male refugee had a long history of disturbed behaviour in Somalia which had continued in the United Kingdom. He was brought for advice when his family in London felt unable to cope with him. Schizophrenia or khat-induced psychosis were possible diagnoses. He had a period of in-patient care at the Maudsley Hospital and a diagnosis of schizophrenia was made after consultation with the Project. In addition, it was found that the patient's recent weight loss was due to gut infestations. Drug treatment has been started. Care in the community is being shared between the hospital and SCP. Medication compliance remains a problem.

Case 4. A 32 year-old married Eritrean refugee was brough to the Project because of feelings of depression, obsessional symptoms and fears of leaving her bed and breakfast hotel room. She attributed her depression to concern about her family; the last information she had of her mother was that she was trying to reach a refugee camp in the Sudan, one brother had recently been killed and she was fearful for the wellbeing of her other brothers and sisters. She was severely depressed with sleep and appetite disturbance and thoughts of suicide, ". . . if I do not see my mother I will die and die". Antidepressants were prescribed after consultation with the family doctor and obsessional checking was treated with behavioural methods. She was encouraged to attend English classes. She improved when her mother, who had travelled for ten days to get to a phone, contacted her from a city in the Sudan. The patient became depressed again the following year and insisted that she had to return to Africa to try to contact her family. The Project advised the client and her husband in regard to documentation and ongoing contact with the Home Office.

Case 5. A 27 year-old female refugee was brought to the Project six weeks after her arrival in the United Kingdom. She had a ten year history of epilepsy treated with a combination of carbamazepine, phenobarbitone and clonazepam. Misunderstandings with the GP and with the local teaching hospital led to her running out of phenobarbitone and carbamazepine and she suffered frequent generalised epileptic seizures. We arranged admission to the Maudsley Hospital and, when fits continued, to Kings' College Hospital. She had petit mal status epilepticus and up to 15 grand mal seizures per day which were controlled during admission. Follow-up is by the neurologists at King's College Hospital with occasional advice from the SCP. The Project is currently trying to obtain rehousing for this client.

Case 6. A 26 year-old divorced female refugee came to the Project complaining of long-standing feelings of depression and anxiety, which had been worsened by recent stresses. She had two mentally and physically handicapped children, one of whom had been taken into care. Her current accommodation was in a basement room in a bed and breakfast hotel. On mental state examination she was depressed and tearful with ideas of guilt and hopelessness. She believed that a man was inside her who, at times, would talk to her and control her actions - a phenomenon known as wadado in Somalia. Her mental state improved following a Somali healing ritual (called oudis) organised by women of the local community. She continues to receive supportive psychotherapy from the SCP who also act on her behalf in her contact with Social Services.

\section{References}

AMNESTY INTERNATIONAL (1984) Torture in the Eighties. London: Amnesty International Publications.

BERRY, J. W. (1988) Acculturation and psychological adaptation among refugees. In Refugees - the Trauma of Exile (ed., D. Miserez). Dordrecht: Martinus Nijhoff.

FERNANDO, S. (1984) Racism as a cause of depression. International Journal of Social Psychiatry, 30, 41-49.

KRIKORIAN, A. D. (1984) Khat and its use: an historical perspective. Journal of Ethnopharmacology, 12, 115-178.

LiTtLEWOOD, R. \& LiPSEDGE, M. (1988) Psychiatric illness among British Afro-Caribbeans. British Medical Journal, 296, 950-951.

Miserez, D. (ed.) (1988) Refugees - the Trauma of Exile Dordrecht: Martinus Nijhoff. 